\title{
Sturge-Weber syndrome type II treated with PDL 595 nm laser
}

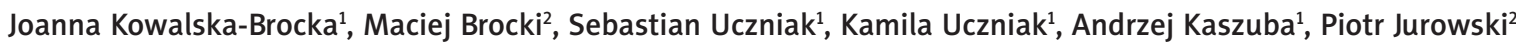 \\ 'Department of Dermatology, Pediatric Dermatology and Oncology, Medical University of Lodz, Lodz, Poland \\ Head of Department: Prof. Andrzej Kaszuba MD, PhD \\ 2Department of Ophthalmology and Visual Rehabilitation, Medical University of Lodz, Lodz, Poland \\ Head of Department: Piotr Jurowski MD, PhD
}

Postep Derm Alergol 2015; XXXII, 1: 63-66

DOI: $10.5114 /$ pdia.2014.40948

\begin{abstract}
Sturge-Weber syndrome (SWS) is rare congenital disorder presenting facial port-wine stains (PWS) eye abnormalities and cerebrovascular malformations. The frequency of SWS is estimated at 1 in 50 000. Cerebrovascular abnormalities can be responsible for seizures, hemiparesis, mental retardation and ophthalmologic abnormalities cause intraocular pressure, glaucoma. Etiopathogenesis of SWS remains elusive. We present a case of a 7-year-old girl with SWS type II. A port-wine stain involves the upper right part of half face and has been associated with glaucoma of both eyes. In the Department of Dermatology in 2009-2012 we performed 23 procedures within 2 months. We have been using PDL laser at wavelength $595 \mathrm{~nm}$ and very good cosmetic results were achieved. Given positive treatment effects, the laser therapy of port-wine stains is a method of selection. Port-wine stains in the course of SWS requires a large number of laser treatment.
\end{abstract}

Key words: Sturge-Weber syndrome, vascular malformation, port-wine stain, PDL, glaucoma.

\section{Introduction}

Sturge-Weber syndrome (SWS), known as encephalofacial angiomatosis or cephalotrigeminal angiomatosis, belongs to a group of neurocutaneous diseases called phakomatoses. The term phakomatosis originates from the Greek word phakos, which means "spot, mark" [1]. The pathology of the disease arises from the developmental disorder of all three germ layers. The estimated prevalence of this syndrome is 1 in 50,000 people with a similar incidence in both sexes. There is no association of the disease with the race. Its pathogenesis has not been well understood. Most cases of cephalotrigeminal angiomatosis occur sporadically, but there are known records of the disease which suggest familial, genetic, and hereditary links [2]. Recent studies indicate an abnormal gene expression of fibronectin and other extracellular matrix genes within the brain tissue and the affected skin in patients with SWS, which indicates the presence of somatic mutations $[3,4]$.
Sturge-Weber syndrome is characterized by a facial cutaneous nevus (port-wine stain - PWS) or red wine stains located on the face, usually unilaterally, resulting from an early embryonic vascular malformation. In addition, vascular malformations may coexist within the leptomeninx (leptomeningeal angiomas), which can cause epileptic seizures with concomitant hemiparesis. Angiomas may appear within the eye to cause glaucoma. According to Roach scale classification, there are three types of SWS:

- type I is characterized by leptomeningeal and facial angiomas with or without pre-existing glaucoma;

- type II presents a facial angioma with pre-existing glaucoma;

- type III includes appearance of leptomeningeal angiomas with or without the presence of glaucoma [5-7].

We present a case of a 7-year-old girl diagnosed with SWS type II, and a description of long-term laser treatment of this disease.

Address for correspondence: Joanna Kowalska-Brocka MD, Department of Dermatology, Pediatric Dermatology and Oncology, Medical University of Lodz, 1/5 Kniaziewicza St, 91-347 Lodz, Poland, phone: +48 505156 334, e-mail: kowalskabrocka@tlen.pl Received: 10.10.2013, accepted: 17.11.2013. 


\section{Case report}

In 2009, a 5-year-old girl was admitted to the Pediatric Dermatology and Oncology Department in Lodz with a chief complaint of a red wine stain (PWS) located on the right upper part of her face (Figure 1). Furthermore, she presented glaucoma in both eyes and a right eye choroidal hemangioma. The clinical findings lead to the diagnosis of WSW type II. The patient's mother reported that the stain was present at birth, and it bleaches when pressed on. Port-wine stains was located unilaterally and occupied the part of skin which is innervated by the first branch of the trigeminal nerve (V1). It was gradually increasing in size with the child growth and showed no tendency for regression. Over the years, nevus flammeus underwent color change from light pink to dark red without causing any general symptoms. Laboratory tests revealed no abnormalities. Family history for SWS and PWS was also negative.

Since the age of 4 , the patient has been under constant care of an ophthalmologist. During her first visit, an intraocular pressure (IOP) was measured using Schiøtz tonometer, which confirmed glaucoma. Fundal examination revealed right ocular choroidal hemangioma. In the study of the eye, C/D (cap disc - the ratio of the cavity of the optic disc to the entire disc, with the norm being 0.2) was 0.8 , which indicated early damage of the optic nerve due to glaucoma. The treatment was initiated to reduce intraocular pressure. At 5 years of age, a trans-scleral photocoagulation of the right eye was performed in order to remove choroidal hemangioma. Unfortunately, this treatment did not bring satisfactory results due to retinal detachment at the age of 7 . The patient underwent

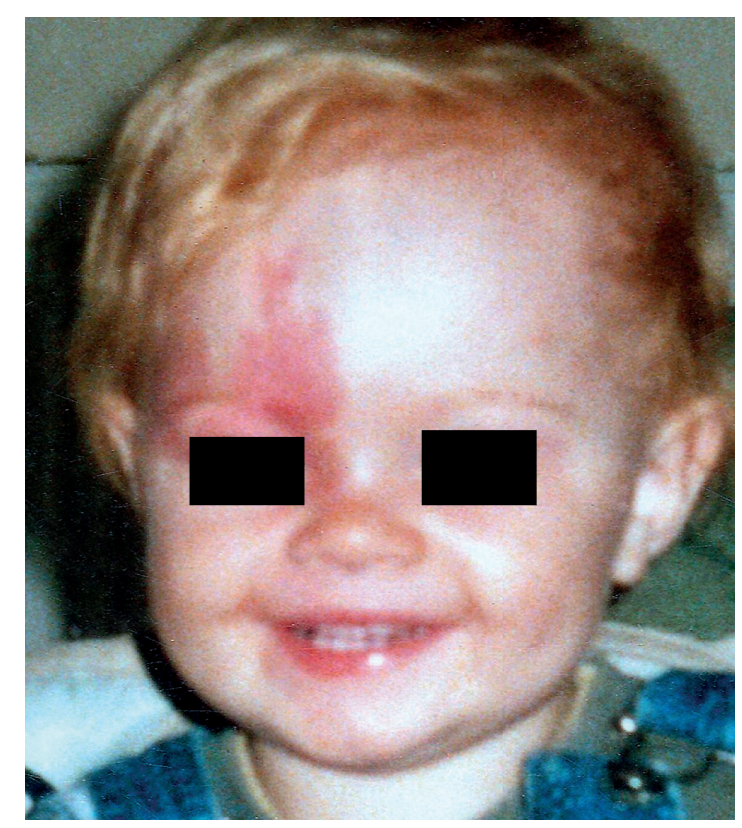

Figure 1. 3-year-old girl. State before laser treatment brachytherapy. 106 Rue applicator (COB5) was implanted in the right sclera. Prior to the brachytherapy, the sclera was $2.4 \mathrm{~mm}$ laterally, $3.8 \mathrm{~mm}$ medially. Post brachytherapy, the result of $2.0 \mathrm{~mm}$ and $2.5 \mathrm{~mm}$, respectively, was achieved. At 4 years old, neuroimaging (electroencephalogram - EEG, computed tomography - CT, and magnetic resonance angiography of the head - MRI) was unremarkable. Furthermore, she gave no history of seizures or mental retardation.

The choice of treatment was non-surgical laser therapy with V-beam $595 \mathrm{~nm}$ pulsed dye laser. In the last 4 years of the patient's hospitalization, we performed a series of 23 laser therapies bimonthly (Figures 2-5). The cosmetic result was excellent, though the healing process has not been yet completed. We anticipate 10 laser procedures following parameters used during therapy: energy: $11 \mathrm{~J} / \mathrm{cm}^{2}$, diameter: $7 \mathrm{~mm}$, pulse duration $0.45 \mathrm{~ms}$ to successfully complete the treatment.

\section{Discussion}

According to the most recent studies, the highest incidence rate of SWS is observed within the areas, which are innervated by the first branch of the trigeminal nerve (V1), with partial or total occupation of the upper eyelid or extensive vascular malformations of PWS covering the territory of V1 and V2 or V1, V2, V3 at the same time. In a study conducted by Maryam Piram et al. at the University Hospital in Tours, France, it was found that the most common locations of hemangiomas in the course of SWS are in the regions occupied by V1 (20\%), V1 and V2 (30\%), V1, V2, V3 (50\%) with fairly frequent bilateral layout changes (40\%) [8]. All patients with PWS located within the V1 should be subjected to ophthalmologic examination. Congenital glaucoma develops in about 30\% of patients. According to data from literature, as much as 95\% of the PWS are localized within the area innervated by $\mathrm{V} 1$ and $\mathrm{V} 2$. Isolated occupation of V1 area only concerns about $8 \%$ of patients [8-10].

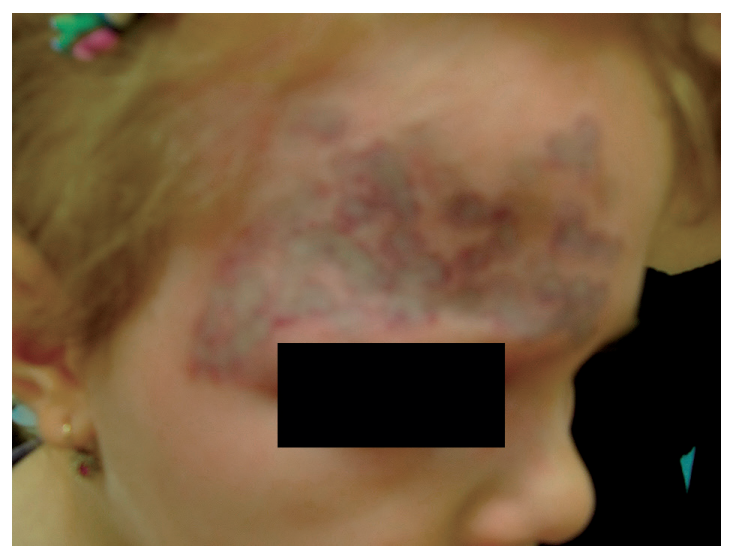

Figure 2. 5-year-old girl, PWS immediately after 10 laser treatment procedures 


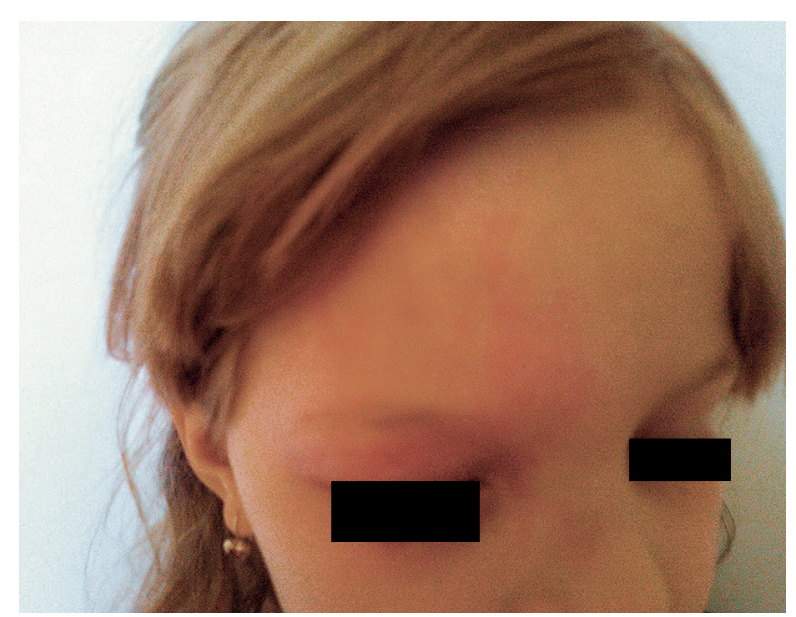

Figure 3. 6.5-year-old girl. Effect after 18 laser treatment procedures

In the presented case, a 7-year-old girl with SWS type II, in whom PWS occupied the upper right eyelid and the right half of the forehead, with coexisting glaucoma was admitted to the Pediatric Dermatology and Oncology Clinic in Lodz. It is worth noticing that the child was not subjected to any neurological or ophthalmological examination after birth despite the apparent vascular malformation with a typical location for SWS. Vascular malformations in the region innervated by V1 should always be an indication for further diagnosis. According to various sources, typical manifestation age of SWS is between 6 months and 2 years old.

The following article presents the effectiveness of the PDL 595 nm laser in the treatment of PWS in a 7-year-old girl with SWS. The achieved result is similar to those obtained in other clinical centers using an identical laser. So far, the ideal age to begin laser treatment therapy is yet to be determined. Most published studies believe that, in order to ensure proper psychological development of a child, PDL laser therapy should be applied as soon as possible. The best outcomes of PDL laser treatment are achieved in infants and small children. Since the malformation growth is proportional to age, the untreated PWS can lead to hypertrophy of the skin in later life. Hence in adults, changes of a more intense, darker color and uneven skin surface require a longer course of laser procedures.

Another advantage of the described therapy is the fact that the PDL $595 \mathrm{~nm}$ laser is equipped with a cooling device, Dynamic Cooling Device (DCD), which protects the skin from heat damage, and reduces pain during the procedure. The DCD can be an advantage when administering therapy in children due to general anesthesia omission. Moreover, excellent cosmetic results, healing without scarring and quick recovery period give great comfort to patients. Nevertheless, a requirement to per-

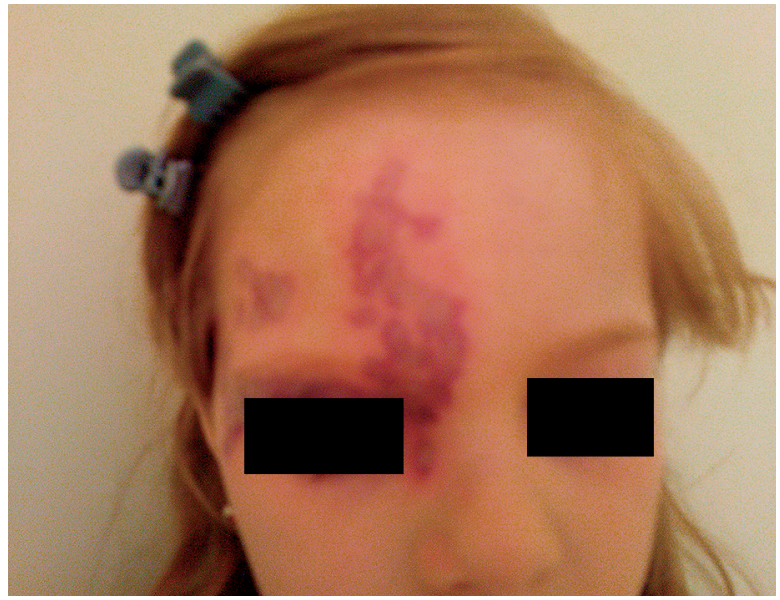

Figure 4. 6.5-year-old girl. Port-wine stain immediately after 19 laser treatment procedures

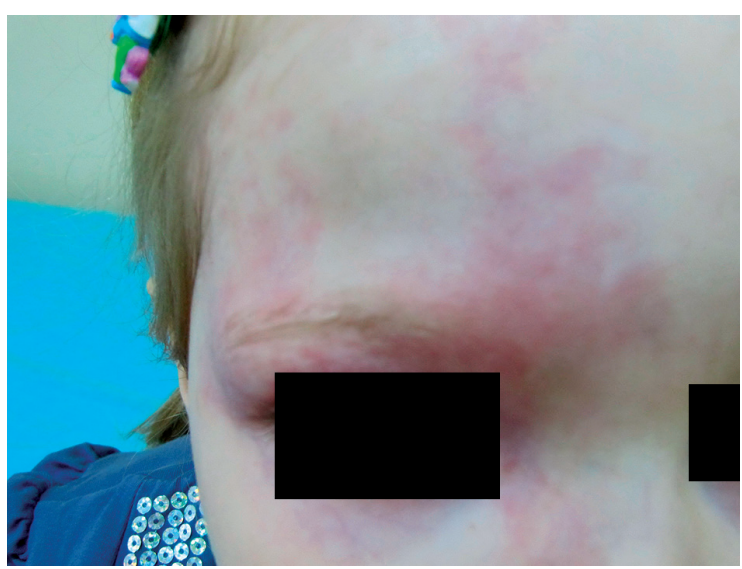

Figure 5. 7-year-old girl. Effect after 23 laser treatment procedures

form multiple PDL laser treatments to obtain maximal effects should be emphasized to patients. The overall excellent clinical result obtained using PDL 595 nm laser, in treating port-wine stains in SWS further suggests the effectiveness of the method [11-13].

\section{Conflict of interest}

The authors declare no conflict of interest.

\section{References}

1. Domańska-Pakieła D, Kaczorowska M, Borkowska D. Forum professors neuro-cutaneous disease - advances in diagnosis and treatment. Przegl Derm 2009; 96: 133-41.

2. Braun-Falco O, Burgdorf WHC, Plewing G, et al. Dermatology. Czelej, Lublin 2010; 831-32.

3. Comi AM, Hunt P, Vawter MP, et al. Increased fibronecton expression in Sturge-Weber syndrome fibroblasts and brain tissue. Pediatr Res 2003; 53: 762-5. 
4. Comi AM. Pathophysiology of Sturge-Weber syndrome. J Child Neurol 2003; 18: 509-16.

5. Rowland LP. Merrit’s neurology. Kwieciński H, Kamińska AM, Urban \& Partner, Wrocław 2004; 100; 591-3.

6. Cohen BA. Pediatric dermatology. Kaszuba A (Ed. Polish). Urban \& Partner, Wrocław 2006; 47-50.

7. Grałek M, Kocyła-Kaczmarewicz B, Niwald A. Glaucoma in the Sturge-Weber syndrome in children adolescents. Okulistyka 2009; 12: 53-5.

8. Piram M, Lorette G, Sirinelli D, et al. Sturge-Weber syndrome in patient with facial port-wine stain. Pediatr Dermatol 2012; 29: 32-7.

9. Sharon S, Swamy B, Taranach DA. Port-wine vascular malformations and glaucoma risk in Sturge-Weber syndrome. J AAPOS 2009; 13: 374-8.

10. Sujansky E, Conradi S. Sturge-Weber syndrome: age of onset of seizures and glaucoma and the prognosis for affected children. J Child Neurol 1995; 10: 49-58.

11. Yung A, Sheehan-Dare R. A comparative study of 595-nm with $585-\mathrm{nm}$ pulsed dye laser in refractory port wine stains. Br J Dermatol 2005; 153: 601-6.

12. Chapas AM, Eickhorst K, Geronemus RG. Efficacy of early treatment of facial port wine stains in newborns: a review of 49 cases. Lasers Surg Med 2007; 39: 563-8.

13. Jasim ZF, Handley JM. Treatment of pulsed dye laser-resistant port wine stain birthmarks. J Am Acad Dermatol 2007; 57 . 677-82. 